\title{
Covid-19: Third of surgeons do not have adequate PPE, royal college warns
}

\section{Abi Rimmer}

The BMJ

Over half of surgeons and trainees in the UK have experienced shortages of personal protective equipment (PPE) in the past month, the Royal College of Surgeons of England has found.

Meanwhile, the BMA has warned that doctors are being forced into impossible situations because of dangerously low levels of PPE.

The Royal College of Surgeons of England conducted a survey on PPE from 6 to 9 April 2020, which received 1978 responses from surgeons and surgical trainees. A third $(32.5 \%)$ of respondents disagreed that PPE supply at their trust was adequate and enabled them to do their job as safely as possible. More than half $(57 \%)$ described shortages of PPE in the past 30 days.

On 10 April the BMA said it was aware that PPE supplies in London and Yorkshire were not sufficient and that the government was forcing doctors to place themselves and their patients in grave danger.

On the same day, the government set out its UK-wide plan to ensure that PPE was delivered to frontline staff. The three strand plan includes guidance on who needs PPE, as well as information about distribution and future supply. ${ }^{1}$ As part of the plan, the government said that a national supply and logistics network had been created to manage supply and demand of PPE around the UK.

\section{New supply chains}

England's health and social care secretary, Matt Hancock, said, "There is a herculean effort behind the scenes, supported by the military, to get the right kit to our frontline heroes. These new supply chains, matched with a call to arms for more businesses and organisations to join this national effort, will help save lives."

However, Chaand Nagpaul, BMA council chair, said that frontline staff did not want a plan-they wanted PPE made available now. He said, "We cannot continue like this, and we need to see enough, adequate, PPE delivered to staff across the country as soon as possible, not just for our health but also, and most importantly, our patients."

Responding to the PPE plan, Chris Hopson, chief executive of NHS Providers, said that NHS trusts were reporting improvements in PPE distribution but that problems remained. "In particular, a number of trusts are reporting that their stocks of gowns are now becoming critically low," he warned.

\section{\#properPPE}

The BMSS \#properPPE campaign is calling for healthcare workers on the front line to be given the appropriate level of PPE. We are calling for doctors to have the correct PPE for each clinical setting, for PPE of sufficient quality and quantity, and for doctors to be given what they need to make them feel safe.

Share your stories with us on social media by using \#properPPE or by email at newsdesk@bmi.com. We want to hear about experiences so that we can push governments to act.

Department of Health and Social Care. Coronavirus (COVID-19): personal protective equipment (PPE) plan. 10 Apr 2020. https:/www.gov.uk/government/publications/ coronavirus-covid-19-personal-protective-equipment-ppe-plan.

Published by the BMJ Publishing Group Limited. For permission to use (where not already granted under a licence) please go to http://group.bmj.com/group/rights-licensing/ permissions 